\title{
ECO-INNOVATIONS - TOOLS FOR THE TRANSITION TO GREEN ECONOMY
}

\author{
Katarzyna Tarnawska \\ Cracow University of Economics, Poland

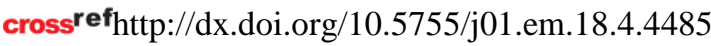

\begin{abstract}
Eco-innovations remain a basic source of green growth and resource efficiency leading to a greater sustainability and at the same time to a technological change. The paper covers the discussion on the methodological controversies related to eco-innovations' importance for the economy. The main purpose of this study is to present in a theoretical way the role of ecoinnovations in the transition to green economy and a current state of eco-innovativeness performance in the EU Member States. Special emphasis is put on the measurement dilemma related to eco-innovativeness performance assessment.

The literature review suggests that there are two approaches concerning the significance of eco-innovations for the economy eco-efficiency and resource efficiency. Eco-innovations are also one of the main sources of green growth. The proper measurement of eco-innovativeness performance remains a serious problem although several projects sponsored by OECD and the EU have tried to address this issue. The current performance of the EU Members States regarding ecoinnovations roughly coincides with the general innovativeness performance with some variations concerning the eco-innovation activities and eco-innovation outputs.
\end{abstract}

The type of the article: Theoretical article.

Keywords: eco-innovation, eco-innovation indicators, green growth, green economy.

JEL Classification: O31, O33.

\section{Introduction}

The problem of the eco-innovations development is not new but its significance is rising as the eco-innovations are perceived as one of the main tools of the transition of economies to green economies. The paper is focused on theoretical considerations. The research methodology employs a desk research and a comparative analysis of the eco-innovation indicators. The paper provides a solid review of literature on eco-innovations with a special emphasis on their role in the transition to green economy. Eco-innovations measurement is one of the key issues as performance assessment provides signals for decision making purposes concerning economic development strategies. Therefore the analysis gives insights into the eco-innovation measurement approaches highlighting their strengths and weaknesses in perspective of their practical usage.

\section{Theoretical background}

There are two streams in economic theory which take into account the natural environment, environmental economics and ecological economics (Pollit et al., 2010). The environmental economics being an extension of the neoclassical economics focuses on the efficient use of (nonrenewable) resources and the negative eternal effects from economic activities. It explains also how to assess environmental policy instruments like taxes and trade able permits (so called market-based instruments) as well as regulatory regimes driven by technical standards. Ecological economics is described as "economics for sustainable development" or "sustainability economics" as it is oriented toward the normative vision of sustainability. Institutions and politics are perceived as important factors. According to this approach the economic system is embedded in a larger 
environmental system which is a source of inputs and a sink for waste. Therefore indefinite growth is unrealistic due to scarcities of resources and consequences of human activities influencing climate change. Substitution of resources by human capital is not possible. There are two important questions from the perspective of ecological economics: how to identify and promote technologies which help to reach sustainability targets and whether the focus on technologies is too narrow and a broader concept of innovation is needed (Rennings, 2000).

In the context of current ecological problems and economic crisis two approaches toward future economic development options can be identified: so called "green growth" and a vision of progress oriented on moderate consumption levels and greater equity (Pollit et al., 2010).

Green growth may be defined as "fostering economic growth and development while ensuring that natural assets continue to provide resources and environmental services on which well-being relies" (OECD, $2011 \mathrm{c})$. It implies greener behavior of firms and consumers, reallocation of jobs, capital and technology towards greener activities and green innovation. In consequence relative or absolute decoupling of economic growth from resource usage can be achieved. Relative decoupling means reduction of resource use per unit of value added while absolute decoupling is related to a stable or declining resource use combined with the growth of economy.

Another strand of literature treats ecological innovation as an example of a technological transition which meets the needs concerning reduction of both environmental impact and the use of natural resources (Ekins, 2011). Eco-innovation may lead to such a transition and it is closely related to change which is in line with evolutionary approaches. The theories of technological transitions suggest that technologies are developed through technology and market signals. So called "technology push" includes R\&D activities leading to technology elaboration while the market decides on its subsequent commercialization (it is pulled by consumer demand).

Geels (2002) looks at "multi-level perspective" of technological transition which comprises the socio-technical landscape (material infrastructure, cultural beliefs, symbols and values), the sociotechnical regime (knowledge, engineering practices, governance structures, manufacturing processes) and the technological niche (spaces insulated from competitive challenges where innovation can survive and develop). Niche markets may be described as small, focused portions of larger markets providing products and services not delivered by mainstream providers. They can be incubators for new technologies demanded by particular groups of consumers. e. g. "green" ones (Ekins, 2011).

Rennings (2000) stresses that there are several reasons why better understanding of innovation processes is important in perspective of sustainable development paradigm. They include the demand for drastic reductions of environmental burdens, the need to reduce costs induced by environmental regulations, the necessity to achieve the progress in environmental technology, management needs and fulfillment of goals of many sustainability programs and initiatives.

\section{Notion of eco-innovation}

The general definition of innovation is neutral as concerns its content. Eco-innovation may be defined as "the creation of novel and competitively produced goods, processes, systems, services and procedures designed to satisfy human needs and provide a better quality of life for everyone with a life-cycle minimal use of natural resources per unit output and minimal release of toxic substances" (Reid, Miedzinski, 2008). A very similar definition can be found in Eco-innovation Observatory Report (EIO, 2013) where eco-innovation is interpreted as: "the introduction of any new or significantly improved product (good or service), process, organizational change or marketing solution that reduces the use of natural resources and decreases the release of harmful substances across the life-cycle". For the purposes of eco-innovation measurement, EIO limits ecoinnovation to activities which reduce material flows.

Kemp and Pearson (2008) define eco-innovation as "the production, assimilation or exploitation of a product, production process, service or management or business method that is novel to the organisation (developing or adopting it) and which results, throughout its life cycle, in a reduction of environmental risk, pollution and other negative impacts of resources use (including energy use) compared to relevant alternatives.". This approach has three important characteristics: 
eco-innovation is subjective, all new processes that are more resource efficient are eco-innovations (also "unintended" eco-innovations), and finally eco-innovations should have real effect on the firm environmental impact (Horbach, Rammer, Rennings, 2012).

According to OECD (2009), eco-innovation is much related to sustainable manufacturing. Although this notion does not have one widely accepted definition, OECD describes sustainable manufacturing citing the Lowell Center for Sustainable Production at the University of Massachusetts as "the creation of goods and services using processes and systems that are: non-polluting, conserving of energy and natural resources, economically viable, safe and healthful for workers, communities, and consumers, and socially and creatively rewarding for all working people".

EU combines development of eco-innovations with accomplishment of wider sustainable development goals. According to the European Commission (2011 b) "eco-innovation is any form of innovation resulting in or aiming at significant and demonstrable progress towards the goal of sustainable development, through reducing impacts on the environment, enhancing resilience to environmental pressures, or achieving a more efficient and responsible use of natural resources.

For business purposes the World Business Council for Sustainable Development (WBCSD, 1996) defines eco-efficiency as a state that can be reached through "the delivery of competitively priced goods and services that satisfy human needs and bring quality of life while progressively reducing environmental impacts of goods and resource intensity throughout the entire life cycle to a level at least in line with the Earth's estimated carrying capacity".

Resource efficiency has been acknowledged at the EU strategic level. This issue became one of the flagship initiatives of the Europe 2020 Strategy aiming to deliver smart, sustainable and inclusive growth (European Commission, 2011a). This initiative aims to create a framework for policies to support the shift towards a resource-efficient and low-carbon economy. It is supported by the Eco-innovation Action Plan (EcoAP) which is at the EU level perceived as "one tool to identify and implement measures for the deployment of key environmental technologies, to enhance coordination and cooperation between the EU and Member States and to generate awareness of the potential of new technologies" (European Commission, 2011b). This perception of eco-innovation is shared by Rennings (2000) who interprets eco-innovations as measures contributing to a reduction of environmental burdens or to ecologically specified sustainability targets.

\section{Method}

Measuring eco-innovation is important for the following reasons (OECD, 2009):

- it is helpful for policymakers who analyse trends in eco-innovation activities and trends in specific product categories,

- it is essential to identify drivers and barriers of eco-innovation,

- it raises awareness of eco-innovation among different stakeholders (businessmen, policymakers, etc.),

- it helps to address environmental challenges.

Andersen (2006) states that eco-innovation indicators should serve the following purposes:

- political signaling, placing a focus on the eco-innovation development rather than the environmental state,

- providing incentives for environmental action among key actors in the innovation system,

- providing new analytical insights into the greening of industry and economy.

Reid and Miedzinski (2008) notice that eco-innovation should be described by a limited number of indicators to show the performance of businesses, economic sectors and national economies concerning how eco-innovation influence key indicators of sustainable development and especially material flow. The indicators could serve then as a guide for management and decision making at different levels of governance. The same remarks refer to the European Eco-Innovation Scoreboard made of several indicators. It can be used to raise the awareness about eco-innovation, and in the policy context as one of the important indicators monitoring progress towards the objectives of the EU Resource Efficiency Roadmap (EIO, 2013). 


\section{Eco-innovation measurement approaches}

It is not easy to measure eco-innovation especially in the field of social and institutional innovation. In general the "object approach" or the "subject approach" can be taken into account (Andersen, 2006). The object approach is focused on the characteristics of individual innovations while the object approach focuses on the innovative behavior of the enterprise a whole. In analyzing the innovation object, the linear model of innovation is considered: from the formulation of an idea to the marketing activities. Therefore the eco-innovation indicators should grasp the competence (R\&D investment, skills and education, organizational development), innovation output (eco-efficiency, patents) and market penetration (market shares, trade). As far as the innovation subjects are investigated, the following indicators may be used: organizational development (e. g. CSR/EMS data), ecoentrepreneurship, financial sector, knowledge institutions and education, knowledge flows, governance and institutional set up. From this perspective the innovation system is a core element of the analysis and the emphasis is put on how the sub-elements of the system work effectively together as a whole.

For the measurement purposes, OECD (2009) proposes the input-output approach. The input measures take into account $R \& D$ expenditures. They are however very serious problems to obtain such data especially for the private sector. OECD distinguishes three types of output measures: intermediate, direct and indirect. The intermediate output measures comprise patents, scientific publications and citations. The patents are only proxies of innovative activities as they do not become innovation if a new idea was not finally commercialized. On the other hand there are databases of eco-innovations identifying both the end-of-the-pipe environmental inventions and "more integrated technological innovations". The direct output measures cover e. g. descriptions of individual innovations, sales of new products form innovations. There are serious difficulties to obtain such information; it can be done by sampling the new products announcements or by examining product information provided by producers. The indirect impact measures include eco-efficiency defined as a relation of environmental impact to product or service value. If this ratio improves it is indicative of eco-innovation. It can be calculated both for micro, meso and macro levels. There are similar indicators measuring indirect impact measures like ecological footprint, material flow analysis, material input pre service unit and ecological rucksack. All of them should be interpreted with caution as there is no simple casual relation between eco-innovation and eco-efficiency.

Reid and Miedzinski (2008) focus on measurement of eco-innovation at three levels: micro, meso and macro. According to them "micro level eco-innovation data refers to indicators related to, on the one hand, company performance, and on the other hand, to individual products and processes. From an eco-innovation perspective, the two aspects are closely inter-linked". The higher-level indicators should be an aggregation of data available at a micro level and then linked to the material flow indicators to embed eco-innovation in an overall resource productivity as well as environmental sustainability perspective.

The MEI project identified that survey analysis, patent analysis and digital and documentary source analysis are useful methods for measuring eco-innovation (Kemp \& Pearson, 2008). In the project several categories of indicators were proposed. They are as follows: the firm, the conditions, the linkages, the radical/incremental innovation indicators, the overall performance indicators. Ekins (2011) notices that "the MEI proposed indicators actually focus on the predisposing conditions for environmental improvement rather than on whether the environmental improvement has actually taken place. There are no indicators of environmental performance per se".

In the ECODRIVE the project eco-innovation is defined as a change in economic activity that delivers enhanced economic and environmental performance (Huppes et al., 2008).

One of the most comprehensive measurement approaches enriched with empirical data was developed by European Eco-Innovation Observatory. The general approach of the EIO is the focus on analysing the material flows, resource productivity and decoupling as the indications of ecoinnovative activity which is related to the indirect measures of a technological change. It takes into account four areas of observation: eco-innovation, environment, innovation and socio-economic framework. Databases comprise data on macro and meso levels (EIO, 2012). Based on the definition of eco-innovation, EIO splits the data and indicators into four main areas: eco-innovation, 
environment, innovation and socio-economic. The last three give an overall context of the analysis and the basis to derive eco-innovation indicators. Therefore "eco-innovation feature is not limited to a simple merging of environment and innovation data but builds upon both sections as well as integrates eco-innovation specific data".

The proposed indicators compare the relative performance of EU Member States in the key areas related to eco-innovation, including investments, company performance and economic and environmental outcomes (EIO, 2013). The scoreboard built upon these indicators has three layers: an aggregated one with the overall scoreboard index (one number per country), a second layer with indices from each of the five main components and the third one with single indicators included in each of the components. The five main components describing eco-innovation performance comprise: eco-innovation inputs, activities and outputs, environmental outcomes and socioeconomic outcomes (EIO, 2012).

\section{Role of eco-innovation in the transition towards green economy}

OECD (2011) approach recognizes that "the central feature of a green growth framework is recognition of natural capital as a factor of production and its role in enhancing well-being". At the same time natural capital is often undervalued and mismanaged and substitution physical capital for natural one can be extremely costly and inhibiting growth possibilities. OECD notices that "limited substitution possibilities between natural and physical capital and the fact that the quality of natural capital can change abruptly also introduces the potential for bottlenecks which can choke off growth".

One of the principal sources of the green growth understood as combining a cleaner economy with a stronger economy is innovation. It can be analyzed as incremental innovation modifying and improving existing techniques, disruptive innovation which changes how things are done or specific technological functions are fulfilled or radical (systemic) innovation leading to fundamental changes of technologies. Eco-innovation goes of course beyond technological issues and may refer to organizational issues, society or institutional matters. According to OECD (2011 b) "innovation affecting green growth may include all the types of innovation, throughout every economic sector and application. While some new innovations and applications that can drive green growth are already materialising, innovation is by its nature unpredictable and important and sometimes radical innovations may emerge that are not yet foreseen".

In order to decouple growth from environmental pressures and to do this at the least possible cost, significant innovation - implying both the creation of new products, processes and technologies, as well as their diffusion and application - will be required.

OECD (2011 d) proposed the following groups of green growth indicators:

- indicators monitoring the environmental and resource productivity of production and consumption;

- indicators describing the natural asset base;

- indicators monitoring the environmental dimension of quality of life,

- indicators describing economic opportunity and policy responses.

The above groups of indicators are accompanied by socio-economic contextual ones.

Technology and innovation is one of the components of the economic opportunity and policy responses indicator. It can be measured through the following indicators:

- R\&D expenditure of importance to green growth:

- renewable energy (in \% of energy related R\&D)

- environmental technologies (in \% of total R\&D, by type)

- all purpose business R\&D (in \% of total R\&D)

- Patents of importance to green growth (in \% of country applications under the Patent Cooperation Treaty):

- environmentally related and all-purpose patents

- structure of environmentally related patents.

- Environment-related innovation in all sectors. 


\section{Results}

Figure 1 presents the overall European Eco-Innovation Scoreboard results for the years 20102012.

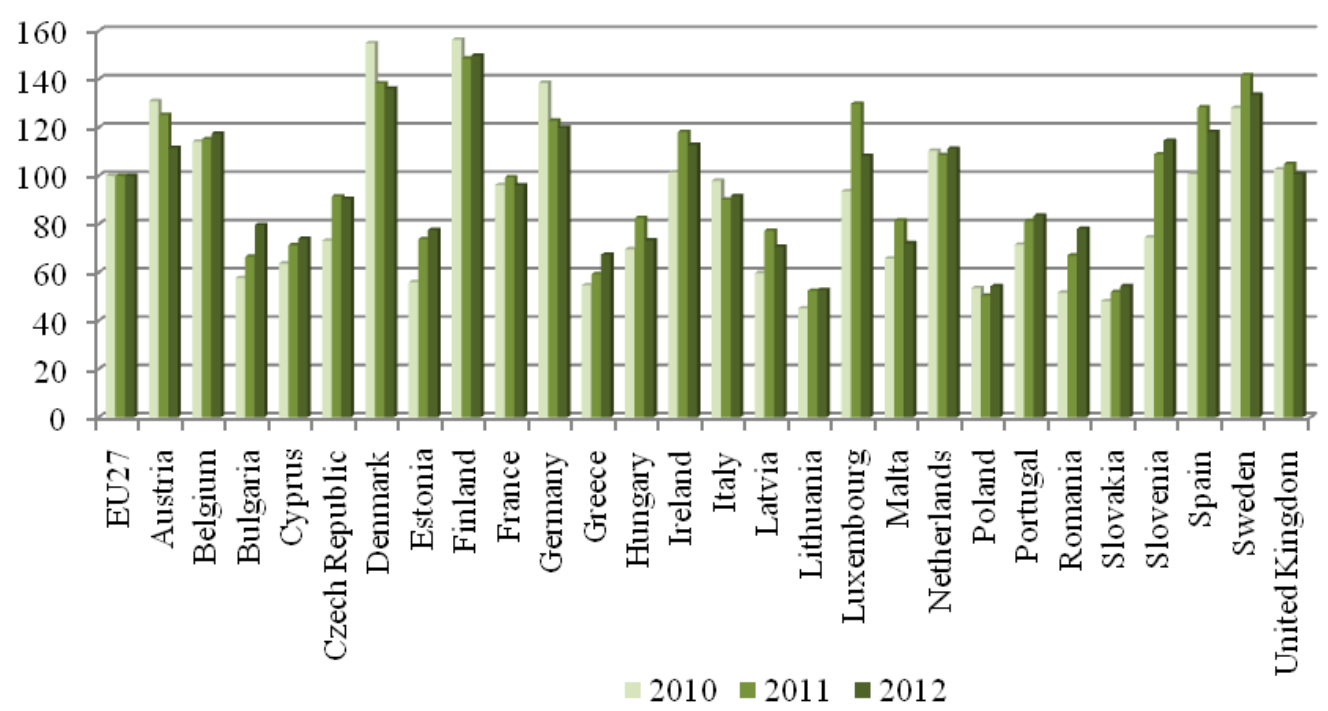

Figure 1. Eco-Innovation Scoreboard 2010 - 2012: the overall index Source: Eco-Innovation Observatory database 2013

There are no major changes during this period however some variations can be observed. Some countries below the EU average, Bulgaria, Cyprus, Estonia, Greece, Portugal, Romania and Slovakia increased their index while some countries like the Czech Republic, Hungary, Latvia, Malta and Poland revealed more alterations. The most remarkable progress was achieved by Slovenia while Austria, Denmark and Germany decreased significantly their index. The reasons for these should be investigated at the particular country level.

Figure 2 illustrates the relative performance of the EU Member States regarding ecoinnovations activities. The 2011 index for this area is calculated based on three indicators: implementation of innovation activities to reduce material inputs per unit of output in companies, implementation of innovation activities to reduce energy inputs per unit of output in companies and firms with environmental management (ISO 14001) systems.

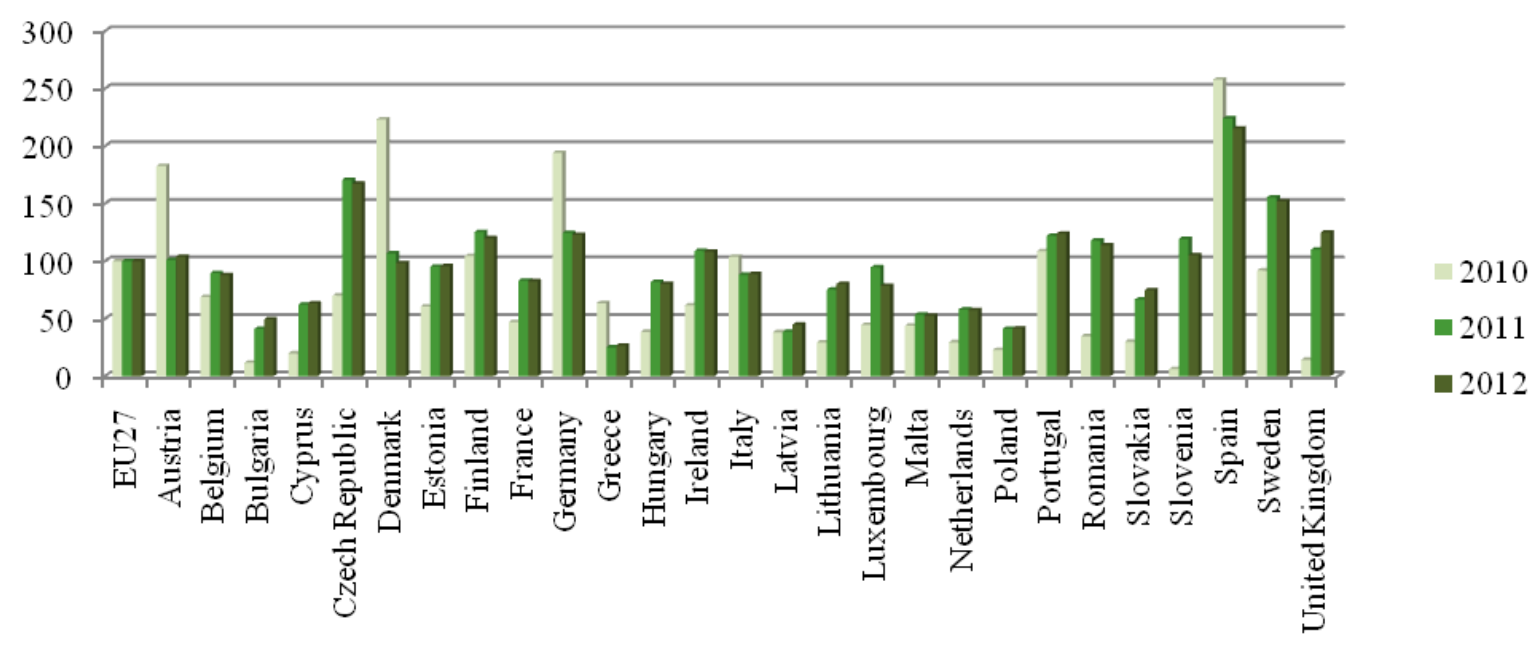

Figure 2. Eco-innovation activities in the EU

Source: Eco-Innovation Observatory database 2013 
In 2012 Spain, the Czech Republic and Sweden were the leaders in eco-innovation activities while Greece, Poland and Latvia achieved the worst scores. These results coincide roughly with the overall index values, with some exceptions (e.g. Romania, Bulgaria, Portugal, the Czech Republic, Luxembourg, the Netherlands and Belgium). The data on the eco-innovation activity reveal huge time variations. Several Member States like Austria, Denmark, Germany, Greece and to a lesser degree Italy and Spain deteriorated their relative score in 2011 in comparison to 2010 while the other ones made a huge progress (Bulgaria, Cyprus, Romania, Slovenia, and the United Kingdom).

Less variation is seen concerning eco-innovations outputs. The 2011 index for this area is based on three indicators: eco-innovation related patents, academic publications related to ecoinnovation and coverage of "eco-innovation" in electronic media. The results are presented in the Figure 3.

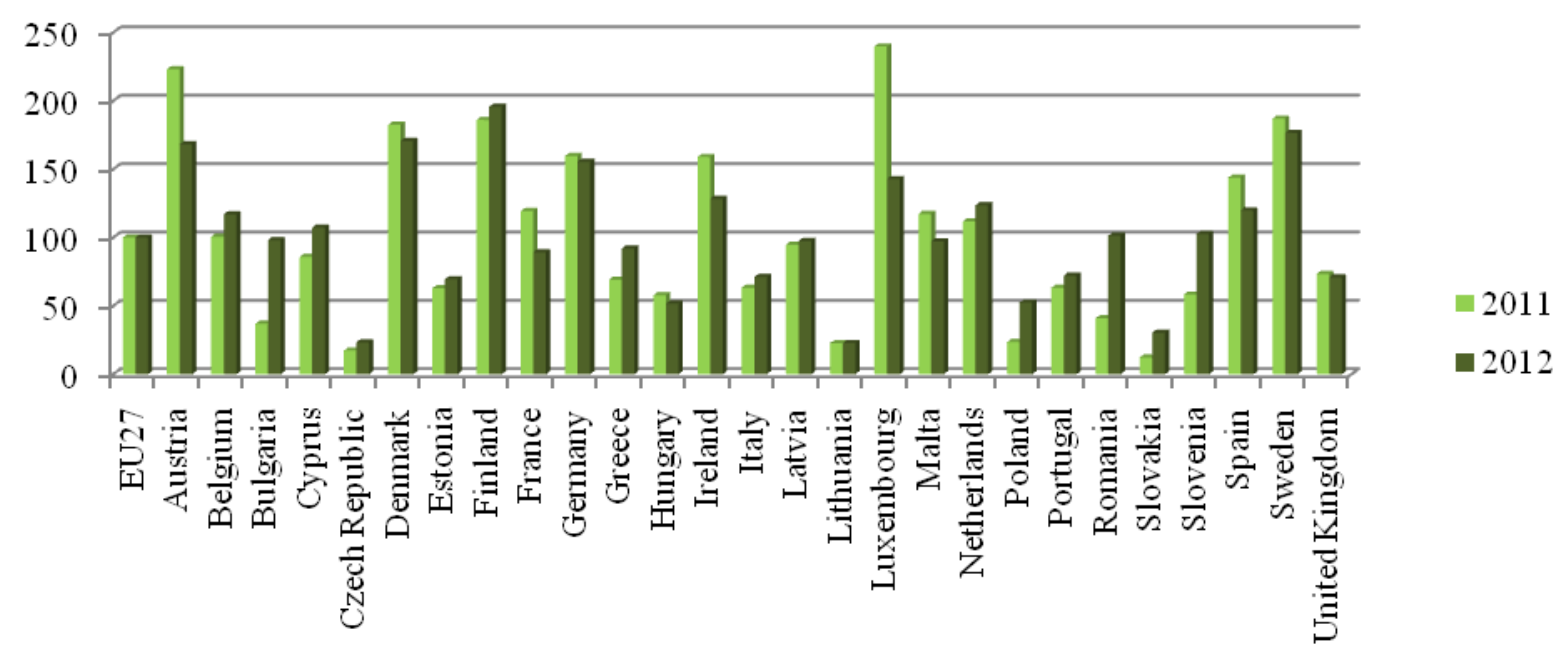

Figure 3. Eco-innovation outputs in the EU

Source: Eco-Innovation Observatory database 2013

In 2012 Lithuania, Czech Republic and Slovakia had the lowest values of the index but at the same time Slovakia increased its score by 147\%. Denmark, Sweden and Finland had the highest values of this index. Luxembourg, France and Austria deteriorated their positions most, while Bulgaria, Slovakia, Romania and Poland made the most impressive progress.

\section{Discussion}

The problem of eco-innovations is currently well grounded in the theory as it is an example of a concrete strategy aimed at the sustainability through diminishing a negative impact on environment. While ecological economics is focused on technologies, the eco-innovation is a broader concept comprising organizational, cultural and social aspects. Eco-innovations remain as well a basic source of green growth and resource efficiency leading to a greater sustainability and at the same time a technological change.

The definitions of eco-innovation suggest that there are two approaches to ecoinnovativeness: eco-efficiency and resource efficiency. The eco-efficiency is understood as an improvement of the quality of environment and hence the quality of life. Resource efficiency is valued especially at firm level as it leads to the decrease in production costs and consequently boosts the competitiveness. Moreover the eco-innovations are not limited to the "end-of-pipe" technology but they refer to a life cycle basis. It is surprising however that a very limited number of eco-innovation notions refers to amelioration of economic performance. This means that the ecoinnovation is almost solely regarded as an instrument of sustainability and the increase in the economic performance is treated only as a by-product of the increase in the resource efficiency. On the other hand the eco-innovation is a source of green growth. 
One of the main challenges referring to the research on eco-innovations is their proper measurement. Measurement is important for various reasons but its policy signaling function goes to the fore. There have been many attempts made to create a comprehensive measurement system undertaken mainly by OECD and through EU sponsored projects. It seems that the most reasonable framework is input-output approach as it provides a clear transmission between inputs in the ecoinnovation development including financial public and private spending and eco-innovation processes results. The measurement approach developed by the Eco-Innovation Observatory is the most advanced, comprehensive and follows the logic of general innovation scoreboards. It combines 16 partial indicators whose values are available. The framework is still under the methodological development but it gives a chance to obtain eventually a detailed picture of ecoinnovativeness in the EU Member States. The main problem with measurement of the ecoinnovativeness performance is the availability of data. Different measurement approaches (OECD, the MEI, the ECODRIVE projects) focus on important determinants and results of ecoinnovativeness activities but although they often indicate the data sources, in practice a lot of data is missing. This is the main weakness of such approaches that should be addressed in the nearest future.

Current performance of the EU Members States regarding eco-innovations roughly coincides with general innovativeness performance with some variations concerning eco-innovation activities and eco-innovation outputs which were analysed in more details as they may be interpreted as intermediate eco-innovations output measures according of OECD classification. Unfortunately there is no good indicator of direct outputs and its elaboration in the nearest future seems to be very difficult.

Eco-innovations are undoubtedly one of the principal tools for the transition to green economy. Therefore they should be supported by a proper public policy at different levels of governance. That is why there is a need to further research on the appropriate measurement framework which will contribute to a better understanding of eco-innovation development barriers and drivers in different EU Member States.

\section{References}

Andersen, M. M. (2006). Eco-innovation indicators, European Environment Agency, February, Copenhagen, http://www.risoe.dk/rispubl/art/2007_115_report.pdf.

EIO (2012). Methodological Report. Eco-Innovation Observatory. Funded by the European Commission, DG Environment, Brussels, August.

EIO (2013). Europe in transition: Paving the way to a green economy through eco-innovation. EcoInnovation Observatory. Funded by the European Commission, DG Environment, Brussels.

Ekins, P. (2011). System Innovation for Environmental Sustainability: Concepts, Policies and Political Economy, in. Bleischwitz at al. (eds.), International Economics of Resource Efficiency, SpringerVerlag, Berlin Heidelberg.

European Commission. (2011a). Communication from the Commission to the European Parliament, the Council, the European Economic and Social Committee and the Committee of the Regions. A resource-efficient Europe - Flagship initiative under the Europe 2020 Strategy, Brussels, 26.01, $\operatorname{COM}(2011) 21$.

European Commission. (2011b). Communication from the Commission to the European Parliament, the Council, the European Economic and Social Committee and the Committee of the Regions. Innovation for a sustainable Future - The Eco-innovation Action Plan (Eco-AP), Brussels, 15.12, COM(2011) 899 final.

Geels, F.W. (2002). Technological transitions as evolutionary reconfiguration processes: a multi-level perspective and a case-study, Research Policy 31, pp 1257-1274. http://dx.doi.org/10.1016/S00487333(02)00062-8

Horbach, J., Rammer, Ch., Rennings, K. (2012). Determinants of eco-innovations by type of environmental impact - The role of regulatory push/pull, technology push and market pull, Ecological Economics, Vol. 78, June. 
Huppes, G., Kleijn, R., Huele, R., Ekins, P., Shaw, B., Esders, M., Schaltegger, S. (2008). Measuring EcoInnovation: Framework and Typology of Indicators Based on Causal Chains. Final Report of the Ecodrive Project, Leiden, London, Lüneburg, 6 March, http://www.europeinnova.eu/c/document_library/get_file?folderId=148899\&name=DLFE-12201.pdf.

Kemp, R, Pearson, P. (2008). Policy brief about measuring eco-innovation and Magazine/Newsletter articles. Deliverable 17 of MEI project, April, UNU-MERIT, http://www.merit.unu.edu/MEI/deliverables/MEI\%20D17\%20Policy\%20brief\%20about\%20measurin g\%20eco-innovation.pdf.

Kemp, R., Pearson, P. (2007). Final report MEI project about measuring ecoinnovation, http://www.merit.unu.edu/MEI/deliverables/MEI\%20D15\%20Final\%20report\%20about\%20measurin g\%20eco-innovation.pdf.

Kronenberg, T. (2009). Finding Common Ground between Ecological Economics and Post-Keynesian Economics, Albacete 23-25 de sept.

OECD (2009). Eco-Innovation in Industry: Enabling Green Growth, OECD Publishing. http://dx.doi.org/10.1787/9789264077225-4-en.

OECD (2011a). Fostering Innovation for Green Growth, OECD Green Growth Studies, OECD Publishing., http://dx.doi.org/10.1787/9789264119925-en.

OECD (2011b). Patents by main technology and by International Patent Classification (IPC), OECD Patent Statistics (database). (Accessed on 15 March 2013).

OECD (2011c). Towards Green Growth, OECD Publishing, May.

OECD (2011d). Towards Green Growth: Monitoring Progress OECD INDICATORS, OECD Publishing.

Pollit, H., Barker, A., Barton, J., Pirgmaier, E., Polzin, Ch., Lutter, S., Hinterberger, F., Stocker, A. (2010). A Scoping Study on the Macroeconomic View of Sustainability, Final report for the European Commission, DG Enviornment, SERI, Cambridge Econometrics, 29 July.

Reid, A., Miedzinski, M. (2008). Eco-innovation. Final report for sectoral innovation watch, Technopolis.

Rennings, K. (2000). Redefining innovation - eco-innovation research and the contribution from ecological economics, Ecological Economics 32, pp. 319 - 332. http://dx.doi.org/10.1016/S0921-8009(99)00112-3

World Business Council for Sustainable Development (WBCSD) (1996), Eco-efficient Leadership for Improved Economic and Environmental Performance, WBCSD, Geneva. 